\title{
DIFERENCIAÇÃO ANATÔMICA DA MADEIRA DE 4 ESPÉCIES DO GÊNERO Caryocar.
}

\author{
Silvana Nisgoski \\ Mestranda em Engenharia Florestal da UFPR. \\ Graciela I. B. de Muñiz e Umberto Klock \\ Departamento de Engenharia e Tecnologia Rurais \\ UFPR - Curitiba, PR
}

\section{RESUMO}

Foi elaborada uma chave de identificação baseada em caracteres anatômicos do xilema. A estrutura das espécies foi analisada em relação à taxonomia, filogenia e utilização da madeira. Os resultados obtidos mostraram que as espécies de Caryocar são muito próximas entre si, tornando-se difícil a identificação das mesmas pelos caracteres anatômicos qualitativos, entretanto, algumas espécies apresentam caracteres muito peculiares, sendo possível separá-las através do diâmetro dos poros e parênquima axial. Pelos gráficos é possível observar algumas variações no comprimento e diâmetro dos vasos e fibras.

\section{SUMMARY}

An identification key based on anatomic characters is furnished. The species structure was analyzed in relation to wood utilization, taxonomy and filogeny. The results show that Caryocar species are much 
similar, so its identification is difficult, but the pores diameter and parenchyma can be used for a separation. The graphics shows this variation.

\section{INTRODUÇÃO}

A família Caryocaraceae é composta por árvores e arbustos dos países da América Latina, compreendendo os gêneros Anthodiscus e Caryocar. As espécies do gênero Caryocar recebem o nome vulgar de pequi, pequiá, pequeá, noz de surana, piqui no Brasil.

O gênero é encontrado no Brasil, Suriname e na Guiana, onde também seus frutos são consumidos pela população local. No Brasil, a área de incidência é vastíssima; estende-se do Amazonas, Pará, Maranhão, Piauí, Goiás, Bahia, Ceará até em São Paulo e Minas Gerais, em menor escala.

A madeira é muito fibrosa, resistente e por isso escolhida para obras que requerem durabilidade e grande esforço contra o esmagamento. A casca fresca e seca do fruto pode substituir a noz de galha na preparação de tinta preta esverdeada de escrever e para tinturaria. O óleo de pequi é considerado como verdadeiro substituto da banha e toicinho que contém colesterol, e ainda com a vantagem de fornecer sabor agradável e cheiro especial. O licor de pequi, preparado com o caroço, tem grandes virtudes, principalmente estomacal e fortificante.

O estudo anatômico, além de possibilitar a identificação das espécies, fornece subsídios valiosos para o conhecimento tecnológico e utilização das madeiras. A identificação de uma amostra de madeira, por sua vez, possibilita a recuperação rápida de informações já adquiridas e catalogadas sobre suas propriedades físico-mecânicas, que são mais ou menos constantes em uma mesma espécie.

Os caracteres anatômicos do lenho também estão sendo cada vez mais empregados em estudos de classificação e filogenia vegetal, tendo adquirido nas últimas décadas considerável importância, tanto por seu 
significado taxonômico, quanto por seu valor na interpretação da evolução das plantas vasculares.

O estudo da anatomia da madeira, no início deste século, começou a ser direcionado às células individualmente, na busca de uma melhor avaliação sobre as propriedades da madeira. Paralelamente, vem sendo constatada uma complexa relação, ligada principalmente a aspectos de distribuição geográfica e disponibilidade de água sobre a anatomia da madeira, atuando na atividade cambial e morfogênese do xilema secundário, modificando a estrutura, propriedades e qualidades da madeira.

De acordo com METCALFE \& CHALK (1965) e RECORD E HESS (1972) o gênero Caryocar apresenta poros médios, solitários e múltiplos radiais de 2-3 células; placa de perfuração tipicamente simples, embora a tendência a formar placas escalariformes tenha sido reportada; tilos presentes e frequentemente abundantes. Pontoações intervasculares alternas, moderadamente grandes. Parênquima predominantemente apotraqueal, como células isoladas ou pequenas linhas tangenciais, podendo ocorrer parênquima paratraqueal aliforme ou vasicêntrico. Raios com mais de 2 células de largura e frequentemente com mais de $1 \mathrm{~mm}$ de altura, os bisseriados com até 7 células de altura; $11-18$ raios $/ \mathrm{mm}$; marcadamente heterogêneos (Kribs tipo II), com margens de células quadradas e eretas. Cristais algumas vezes presentes em células marginais subdivididas, algumas vezes drusas. Fibras com pontoações pequenas, simples, maioria nas paredes radiais; septos raros a comuns; comprimento até $2 \mathrm{~mm}$.

Visando contribuir nos aspectos mencionados, foi efetuado o estudo anatômico da madeira de Caryocar glabrum (Aubl.) Pers., Caryocar barbinerve Miq., Caryocar pallidum A.C.Smith, Caryocar villosum (Aubl.) Pers. buscando uma diferenciação entre as mesmas.

Deste modo, associando os estudos da anatomia da madeira (que permitem identificar e distinguir espécies idênticas; predizer propriedades, pré-julgar sobre o comportamento e possíveis utilizações da madeira) com as características tecnológicas e o comportamento prático das 
madeiras, espera-se contribuir com elementos úteis no sentido de identificálas estruturalmente, bem como incrementar as suas possibilidades de utilização e aproveitamento industrial.

\section{MATERIAL E MÉTODOS}

As espécies estudadas foram: Caryocar barbinerve Miq., Caryocar glabrum (Aubl.) Pers., Caryocar pallidum A.C.Smith e Caryocar villosum (Aubl.) Pers. As amostras foram fornecidas pela xilotecas do IPT, INPA E EMBRAPA.

As amostras de madeira destinadas à obtenção das seções histológicas do xilema foram retiradas aleatoriamente dentro dos discos e orientadas para a obtenção de cortes nos planos transversal, longitudinal radial e longitudinal tangencial. Após o amolecimento por fervura em água, procedeu-se o seccionamento em micrótomo de deslizamento modelo Spencer $A O n^{\circ} 860$, com espessura variando de 14 a 24 micrômetros. As seções foram tingidas pelo método de tripla coloração, com acridina vermelha, crisoidina e azul de astra, sendo posteriormente desidratadas em série alcoólica ascendente, colocadas em xilol e montadas em lâminas permanentes com Entellan.

A maceração dos tecidos componentes da madeira foi efetuada pelo método de Jefrey que consiste no desmembramento através de uma solução aquosa de ácido nítrico e ácido crômico, ambos a 10\%, na proporção de 1:1. Utilizou-se safranina como corante e o processo de desidratação e montagem empregados foram os mesmos descritos anteriormente.

Tanto para as descrições microscópicas como para as mensurações dos elementos celulares individuais seguiu-se as normas ABNT, com alterações introduzidas por MUÑIZ (1991). 
Os dados quantitativos dos caracteres anatômicos obtidos das medições foram processados em computador e obteve-se valores médios, máximos, mínimos e desvio padrão para cada característica estrutural.

Para a tomada das fotomicrografias, foi utilizado um fotomicroscópio Carl Zeiss. O filme empregado foi Kodak-Panatomic x Asa 32 e as ampliações feitas em papel fotográfico Kodabromid F-3 brilhante. Também foi realizada microscopia eletrônica, utilizando filme Vericrhome 120, fixador e papel revelador da Kodak.

\section{DESCRIÇÃO GERAL DA ESTRUTURA DA MADEIRA DAS ESPÉCIES}

Os aspectos anatômicos das madeiras foram observados e descritos. Foram considerados tanto os caracteres qualitativos como quantitativos dos elementos constituintes do xilema secundário. Os valores mínimo, médio, máximo e desvio padrão (s) são apresentados a seguir.

Caryocar villosum (Aubl.) Pers.

Características gerais: Madeira pesada (densidade 0,93 $\mathrm{g} / \mathrm{cm}^{3}$ ), resistente; cerne recém polido, branco levemente rosado, passando geralmente a bege amarelado ou também pardo-claro amarelado; textura grossa; grã diagonal a revessa; superfície irregularmente lustrosa, medianamente áspera, ou áspera ao tato; cheiro suave de fermento ou de vinagre, gosto imperceptível; alta resistência ao ataque de agentes xilófagos; baixa permeabilidade às soluções preservantes.

\section{Características anatômicas:}

Anéis de crescimento: pouco distintos, marcados apenas por zonas fibrosas regulares.

Vasos: visíveis a olho nu, solitários e múltiplos radiais (2-5), porosidade difusa, poros pequenos a grandes de formato oval a arredondados, com diâmetro tangencial de 70- 218 - $350 \mu \mathrm{m} \quad(\mathrm{s}=65,4)$, 
espessura da parede de $10 \mu \mathrm{m}$. Elementos vasculares com comprimento até $950 \mu \mathrm{m}$; placa de perfuração exclusivamente simples. Média de 5 poros $/ \mathrm{mm}^{2}$, variando de 2 a 7 ; tilos presentes em abundância, pontoações intervasculares areoladas, alternas. Às vezes existem apêndices vasculares com até $50 \mu \mathrm{m}$ de comprimento.

Parênquima axial: distinto só sob lente. Apotraqueal difuso e difuso em agregado com linhas se interligando; paratraqueal aliforme escasso. Presença de cristais em câmara.

Raios: numerosos, em média de 14 raios $/ \mathrm{mm}$, variando de 12 a 17. Altura de 8- 25 -47 células com 350-1650 $\mu$ m; heterogêneo tipo II, predominantemente, uni e bisseriados local e totalmente; pontoações raiovasculares grandes, arredondados, simples ou semi-areoladas.

Fibras: libriformes, espessas, longas, comprimento variando de 650 a $2200 \mu \mathrm{m}$, diâmetro de 15 a $25 \mu \mathrm{m}$, paredes espessas (3 a $10 \mu \mathrm{m}$ ).

\section{Caryocar barbinerve Miq.}

Características Gerais: Madeira pesada (densidade 0,85 $\mathrm{g} / \mathrm{cm}^{3}$ ), moderadamente dura ao corte; cerne de cor bege claro pardacento, não diferenciado do alburno quanto a cor, e sim pela presença de tilos que obstruem completamente os vasos do cerne; alburno com aproximadamente $3 \mathrm{~cm}$ de largura; superfície de pouco brilho; textura grossa, grã irregular a revessa; cheiro característico de vinagre quando a madeira está verde; gosto imperceptivel. Resiste bem aos agentes de deterioração; xilófagos; pouco permeável a soluções preservantes.

\section{Características anatômicas:}

Anéis de crescimento: pouco diferenciados, apenas limitados por fibras mais espessas e escuras e parênquima marginal.

Vasos: visíveis a olho nu; porosidade difusa; poros solitários e múltiplos radiais de até 5 , predominando os primeiros; grandes, oval a arredondados, diâmetro tangencial médio de $240 \mu \mathrm{m}$, variando de 200 a 340 
$\mu \mathrm{m}(\mathrm{s}=33)$, espessura da parede em média de $10 \mu \mathrm{m}$. Elementos vasculares com comprimento de $100-400-1000 \mu \mathrm{m}(s=284)$. Placa de perfuração simples. Poros $/ \mathrm{mm}^{2}$ em torno de 5, presença abundante de tilos, pontoações intervasculares circulares, grandes. Presença de óleo-resinas.

Parênquima axial: visível só sob lente, apotraqueal difuso e difuso em agregados, parênquima marginal em finas linhas, às vezes paratraqueal escasso. Cristais em câmara presentes.

Raios: pouco visíveis, só sob lente; numerosos, média de $10 / \mathrm{mm}$, variando de 9 a 13 . Altura média de 27 células, de $450-1650$ um ( $\mathrm{s}=$ 331). Heterogêneo tipo I e II; uni a trisseriados predominando os bisseriados. Pontoações raio-vasculares arredondadas a alongadas, óleo resina presente.

Fibras: libriformes, comprimento de 800 - 1524 - $2550 \mu \mathrm{m}$, ( $s=493$ ); diâmetro de 12,5 a $25 \mu \mathrm{m}(\mathrm{s}=4)$, paredes espessas atingindo até $7,5 \mu \mathrm{m}$. Fibras gelatinosas presentes.

Caryocar glabrum (Aubl.) Pers.

Características gerais: madeira pesada (densidade 0,81 $\mathrm{g} / \mathrm{cm}^{3}$ ); cerne branco levemente amarelado, com alternâncias mais ou menos acentuadas; alburno pouco diferenciado, levemente mais claro; textura grossa; grã diagonal a revessa; superfície irregularmente lustrosa e áspera ao tato; cheiro e gosto imperceptíveis, boa resistência ao ataque de organismos xilófagos, baixa permeabilidade às soluções preservantes.

\section{Características anatômicas}

Anéis de crescimento: pouco distintos, diferenciados apenas por zonas fibrosas.

Vasos: visiveis a olho nu; porosidade difusa; poros solitários a múltiplos radiais de até 5 , grandes, diâmetro tangencial de 150 - $202-250$ $\mu \mathrm{m}(\mathrm{s}=27,8)$, espessura da parede de $10 \mu \mathrm{m}$. Elementos vasculares com comprimento de 200 - 531 - $1100 \mu \mathrm{m}$ ( $(=204)$; placa de perfuração simples. 
Poros $/ \mathrm{mm}^{2}$ em torno de 10, variando de 7 a 13; tilos abundantes, pontoações intervasculares em pares areolados, alternos, fendas inclusas.

Parênquima axial: distinto só sob lente, apotraqueal difuso e subagregado; paratraqueal aliforme raramente. Cristais em câmaras presentes.

Raios: visíveis só sob lente, numerosos, regularmente espaçados de 12 -14- 16 raios/mm; altura de $19-29-34$ células $(s=5,6)$ e de 930- 1233 - $1700 \mu \mathrm{m}(s=197,7)$. Heterogêneo tipo II predominantemente. Uni e bisseriados localmente; pontoações raio-vasculares simples ou semiareoladas de arranjo irregular.

Fibras: libriformes; comprimento variando de 450 - 840 - 2000 $\mu \mathrm{m} \quad(\mathrm{s}=353,9)$; diâmetro médio de 10- 17 - 37,5 $\mu \mathrm{m}(\mathrm{s}=6,2)$, paredes espessas de 5,2 $\mu \mathrm{m}$ em média.

Caryocar pallidum A C.Smith

Características gerais: madeira pesada (densidade 0,81 $\mathrm{g} / \mathrm{cm}^{3}$ ); cerne branco levemente amarelado, com alternâncias; alburno pouco diferenciado, levemente mais claro; textura grossa; grã diagonal a revessa; cheiro e gosto imperceptíveis, boa resistência ao ataque de organismos xilófagos, baixa permeabilidade às soluções preservantes.

\section{Características anatômicas:}

Anéis de Crescimento: pouco distintos, apenas separados por uma linha de parênquima marginal.

Vasos: visíveis a olho nu; porosidade difusa; poros solitários a múltiplos radiais (até 9); diâmetro médio de $150-190-230 \mu \mathrm{m}(\mathrm{s}=26)$; espessura da parede de $10 \mu \mathrm{m}$. Elementos vasculares com comprimento de $1000 \mu \mathrm{m}(\mathrm{x}=481, \mathrm{~s}=24,7)$. Placa de perfuração simples, poros $/ \mathrm{mm}^{2} \mathrm{em}$ torno de 8 , variando de 4 a 14; tilos em abundância, pontoações intervasculares areoladas, alternas. 
Parênquima axial: pouco visível sob lente, apotraqueal difuso, vasicêntrico e marginal. Cristais em séries e máculas medulares presentes.

Raios: numerosos, médio de 14 raios $/ \mathrm{mm}$, variando de 12 a 19 , altura variando de $8-15-28$ células $(s=6,08)$ e $400-748-1500 \mu \mathrm{m}$ $(s=300,8)$, predominam heterogêneos tipo II, uni a bisseriados localmente. Pontoações raio-vasculares arredondadas; óleo resina presentes.

Fibras: libriformes, septadas, comprimento de 400 -973 - 1600 $\mu \mathrm{m}(\mathrm{s}=297)$; diâmetro médio de $20 \mu \mathrm{m}$ variando de 12,5 a $32,5 \mu \mathrm{m}(\mathrm{s}=5,15)$, paredes espessas até $14 \mu \mathrm{m}$.

\section{ANÁLISE DOS ELEMENTOS ESTRUTURAIS DO XILEMA}

Os principais caracteres anatômicos observados nas 4 espécies correspondem à descrição do gênero em literatura, de acordo com METCALFE \& CHALK (1965) e RECORD E HESS (1972).

As espécies estudadas se caracterizam pela presença de placas de perfuração simples. A presença de pontoações intervasculares dispostas em arranjo alterno encontram-se invariavelmente em todas as madeiras analisadas; as pontoações raio-vasculares e parênquimovasculares são semelhantes às intervasculares. Todas as espécies examinadas caracterizam-se pela porosidade difusa, com poros solitários e em agrupamentos múltiplos radiais e racemiformes.

O parênquima axial é tipicamente apotraqueal difuso em agregado com linhas se interligando, sendo encontrado também paratraqueal aliforme escasso.

Os raios são heterogêneos constituídos por células procumbentes, eretas, quadradas e envolventes. A largura dos raios em número de células varia de uni a bisseriados local e totalmente.

A ocorrência de pontoações simples diminutas na parede celular das fibras é característica comum das madeiras estudadas. 
Observaram-se monocristais romboédricos de oxalato de cálcio, pequenos, dispostos em câmaras no parênquima axial das espécies estudadas.
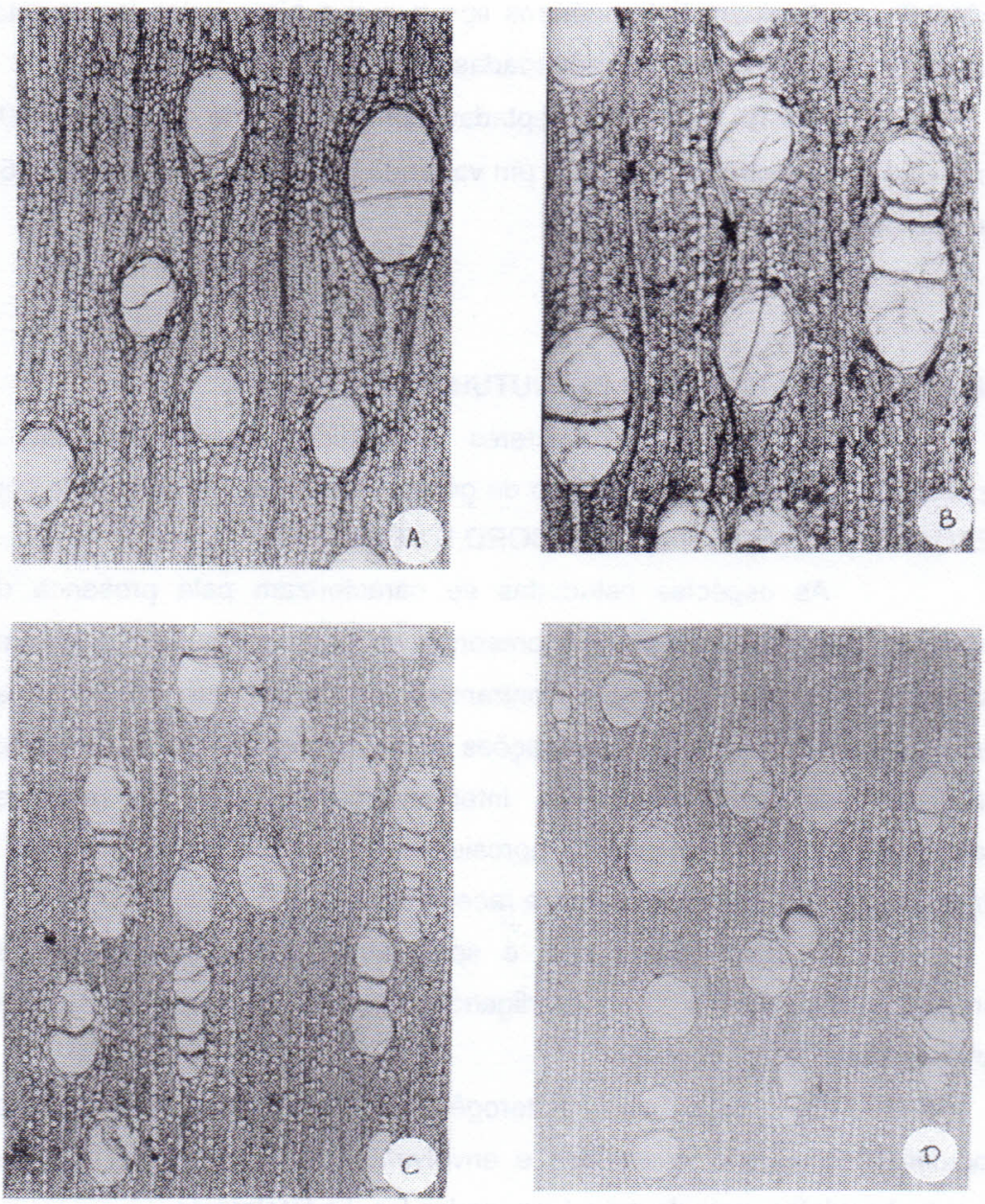

Figura 1 - Seções transversais da madeira (aumento 50x) A) Caryocar villosum (Aubl.) Pers. B) Caryocar barbinerve Miq. C) Caryocar glabrum (Aubl.) Pers. D) Caryocar pallidum A C.Smith 

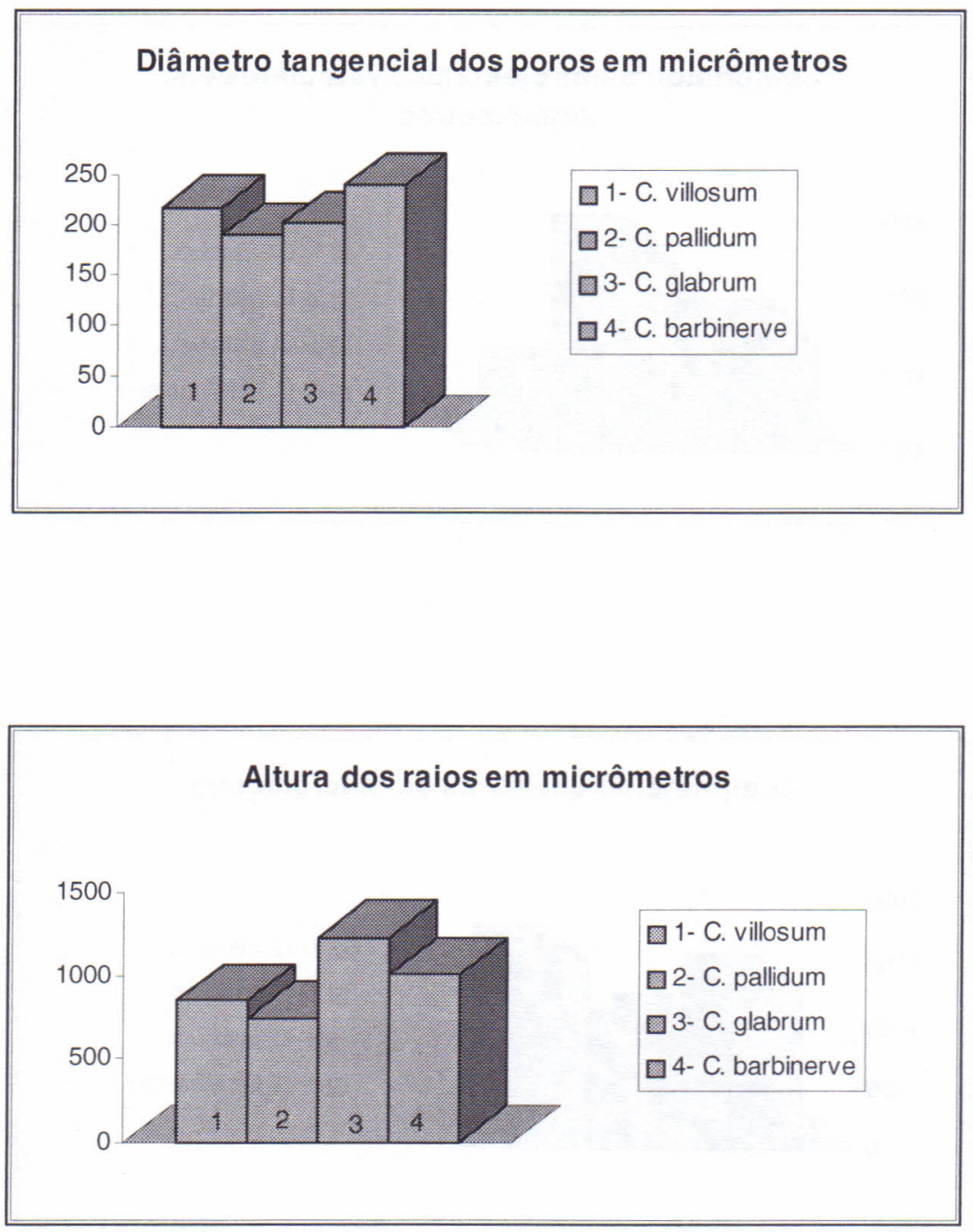

Rev. Ciência e Natura, Santa Maria, 20: 85 - 99 , 1998. 

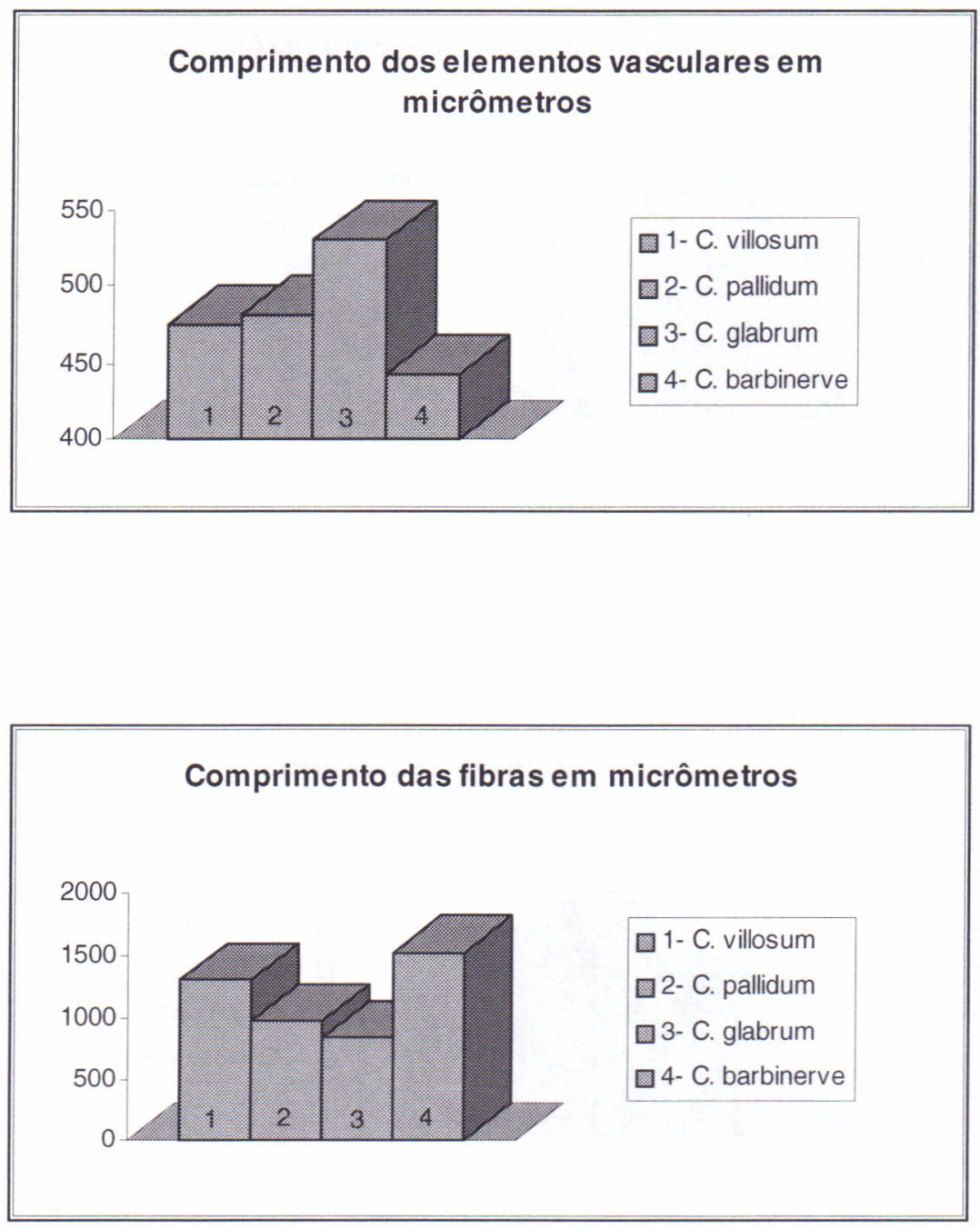


\section{CHAVE DICOTÔMICA}

Para a identificação das espécies estudadas foi elaborada uma chave dicotômica:

1.a) Anéis de crescimento demarcados apenas por parênquima marginal ou em associação com fibras mais espessas e escuras . . . . . . . . .

b) Anéis de crescimento demarcados por zonas fibrosas . . . . . . . 3

2.a) Parênquima apotraqueal difuso e difuso em agregados; poros com diâmetro tangencial de 200-300 $\mu \mathrm{m}$, cinco por $\mathrm{mm}^{2}$; raios uni a trisseriados

Caryocar barbinerve

b) Parênquima apotraqueal difuso e paratraqueal vasicêntrico; poros com diâmetro tangencial de $150-230 \mu \mathrm{m}$, oito por $\mathrm{mm}^{2}$; raios uni a bisseriados

Caryocar pallidum

3.a) Poros com diâmetro tangencial de $70-350 \mu \mathrm{m}$; pouco numerosos; tilos abundantes

Caryocar villosum

b) Poros com diâmetro tangencial de 150-250 $\mu \mathrm{m}$; numerosos; tilos presentes

Caryocar glabrum

\section{CONCLUSÃO}

A análise da estrutura anatômica do Caryocar villosum (Aubl.) Pers., Caryocar barbinerve Miq., Caryocar glabrum (Aubl.) Pers. e Caryocar pallidum A C.Smith permite concluir que: 
- foi possível efetuar uma melhor caracterização das espécies estudadas;

- a diferenciação é difícil uma vez que as mesmas são muito próximas entre si, sendo a separação possível apenas através do diâmetro dos poros e parênquima;

- com os resultados obtidos foi possível a elaboração de uma chave dicotômica a qual fornece subsídios para uma identificação mais rápida.

\section{REFERÊNCIAS BIBLIOGRÁFICAS}

CHIMELO,J.P. Fichas de características das madeiras brasileiras. São Paulo: IPT, 1989.

FILHO,A.M \& ARAÚJO,P.A.M. Estruturas das madeiras de Caryocaraceae. Arquivos do Jardim Botânico do Rio de Janeiro, vol. XIX, Brasil, 1973.

LORENZI,H. Árvores brasileiras - manual de identificação e cultivo de plantas arbóreas nativas do Brasil. São Paulo: Editora Plantarum, 1992.

LOUREIRO,A. \& SILVA, MF. Catálogo das madeiras da Amazônia - Vol. I. Belém: SUDAM, 1968.

MAINIERI, C. Manual de identificação das principais madeiras comerciais brasileiras. São Paulo: IPT, 1983.

METCALFE, C.R \& CHALK, L. Anatomy of the dicotyledons - Vol 1, Oxford, 1965.

MUÑIZ, G.I.B. \& CORADIN, V.R. Normas de procedimentos em estudos de anatomia da madeira: I-Angiospermae, II Gimnospermae. Brasília: Laboratório de Produtos Florestais, Série Técnica 15, 1991.

PEIXOTO,A.R. Plantas oleaginosas arbóreas. São Paulo: Editora Nobel, 1973.

PRANCE, G.T. Árvores de Manaus. Manaus: INPA, 1975.

RECORD, S.J. \& HESS, R.W. Timbers of the New World. New York, 1972.

98 Rev. Ciência e Natura, Santa Maria, 20: 85 - 99 , 1998. 
RIZZINI, CT \& MORS, W.B. Botânica econômica brasileira. São Paulo: EPU, 1976.

RIZZINI,C.T. Árvores e madeiras úteis do Brasil-manual de dendrologia brasileira. São Paulo: Editora Edgard Blucher, 1981.

WILLIANS, L. A study of Caryocaraceae. Trop Woods 42, Yale University, 1935. 
100 Rev. Ciência e Natura, Santa Maria, 20: 85 - 99 , 1998. 